\title{
Defluorinative Carboimination of Trifluoromethyl Ketones
}
Xiaolong Zhang ${ }^{1} \uparrow$, Yongquan Ning ${ }^{1} \uparrow$, Zhaohong $\operatorname{Liu}^{1} \uparrow$, Shuang $\mathrm{Li}^{1}$, Giuseppe Zanoni ${ }^{2}$, Xihe $\mathrm{Bi}^{1,3 *}$

${ }^{1}$ Department of Chemistry, Northeast Normal University, Changchun 130024, China

${ }^{2}$ Department of Chemistry, University of Pavia, Viale Taramelli 12, 27100 Pavia, Italy.

${ }^{3}$ State Key Laboratory of Elemento-Organic Chemistry, Nankai University, Tianjin 300071, China.

*Corresponding author. Email: bixh507@ nenu.edu.cn

\section{Abstract:}

The monofunctionalized carbodefluorination of readily accessible $\mathrm{CF}_{3}$ groups is acknowledged as an attractive approach to the preparation of partially fluorinated molecules. However, their defluorinative difunctionalization remains a challenging and unmet goal. Herein, we report an unprecedented defluorinative carboimination of trifluoromethyl ketones via a strategy of silver carbene-initiated rearrangement, in which both $\mathrm{C}-\mathrm{F}$ bond and carbonyl group of the trifluoromethyl ketones were functionalized simultaneously, thus providing a straightforward synthetic method for medicinally relevant $\alpha, \alpha$-difluoroimines. The current approach involves a silver carbene-initiated intramolecular cascade process by integrating successive cleavage of $\mathrm{C}-\mathrm{F}$ bond and formation of $\mathrm{C}-\mathrm{C}$ and $\mathrm{C}=\mathrm{N}$ bonds on a single molecule entity, which differs relevantly from the stepwise mechanism of reported carbodefluorination of $\mathrm{CF}_{3}$ groups. Mechanistic studies disclose that silver catalysis plays a critical role, particularly in the stages of $\mathrm{C}-\mathrm{F}$ bond cleavage and aza-Claisen rearrangement. 


\section{Main Text:}

The unique physical and biological properties of fluorine atoms led to their ubiquity in pharmaceuticals (1-4), agrochemicals (5), and polymetric materials (6). Among these organic fluorine compounds, $\mathrm{CF}_{2}$-containing molecules have received an increasing attention because of the advantageous effects stemming from the presence of germinal fluorine atoms (7-8) and of acting as more-lipophilic bioisosteres for alcohols and thiols (Fig. 1A) (9-10). Over the past decade, considerable efforts have been devoted to the development of flexible synthetic methods to access these fluorine molecules. Most of the approaches reported so far, however, feature site-selective difluorination and transformations of the pre-installed $\mathrm{CF}_{2}$-groups (11-21). The carbodefluorination of $\mathrm{CF}_{3}$ group has been recognized as one of the most ideal strategies for the synthesis of $\mathrm{CF}_{2}$-containing compounds in view of the abundant amount and low cost of $\mathrm{CF}_{3}$ sources (22-23), despite the challenges posed by the selective cleavage of $\mathrm{C}-\mathrm{F}$ bond of $\mathrm{CF}_{3}$ group, because of the high bond dissociation energy (BDE) and of over-defluorination which is often observed (24-27). In the past decade, impressive advances in the controllable carbodefluorination of $\mathrm{CF}_{3}$ groups have been achieved (Fig. 1B). These strategies generally involve a stepwise mechanism including, after cleaving the $\mathrm{C}-\mathrm{F}$ bond, the generation of reactive intermediates, such as (i) electrophilic carbocation using strong Lewis acids (28-29), (ii) nucleophilic carbanion by low-valent metal or electrochemical reduction (30-32), and (iii) radical generated by singleelectron reduction (33-41). A $\pi$-system (i.e., arene, alkene, and carbonyl groups) is often required to accelerate the elimination of fluorine and/or to stabilize, by the $\mathrm{p}-\pi$ conjugation effect, the in situ generated difluoromethylene intermediates. Nevertheless, only one $\mathrm{C}-\mathrm{F}$ bond could be efficiently carbofunctionalized in such reactions. Very recently, Wang, Houk, and colleagues reported an elegant carbofunctionalization of $\mathrm{CF}_{3}$ groups capable of affording 1,1-dialkylation products by a two-stage iterative defluorinative alkylation of $\alpha$-trifluoromethyl carbonyl compounds via radical spin-center shift, while the $\pi$-system remains unaltered (42). Simultaneous 1,2-difunctionalization of both $\mathrm{C}$-F bond and $\pi$-system of $\pi$ - $\mathrm{CF}_{3}$ molecules would be suitable to achieve more complex partially fluorinated molecules in a single step, however, such a strategy remains unexplored so far (Fig. 1C).

We report herein an unprecedented carboimination of trifluoromethyl ketones via a strategy of carbene-initiated rearrangement, which therefore constitutes the first method of defluorinative 1,2difunctionalization of $\pi-\mathrm{CF}_{3}$ molecules (Fig. 1D) (43-44). Distinct from the stepwise mechanism of previous carbodefluorinations (Fig. 1B), the carboimination reaction proceeds through intramolecular cascade process, involving the initial formation of silver carbene (45-48) followed by the attack of an allylamine to provide the key ammonium ylide; $\mathrm{C}-\mathrm{F}$ bond cleavage is then triggered by selective $\mathrm{HF}$ elimination to form a rearrangeable $\mathrm{N}$-allyl difluoroenamine intermediate and formation of $\mathrm{C}-\mathrm{C}$ and $\mathrm{C}=\mathrm{N}$ bonds is eventually achieved through a rare $a z a$-Claisen rearrangement. Notably, the aza-Claisen rearrangement typically requires harsh reaction conditions (49). Herein, the silver catalyst plays a critical role in the generation of the difluoroalkene intermediate as well as in facilitating the $a z a$-Claisen rearrangement under mild conditions. In addition to the mechanistic novelty, this carbene-initiated rearrangement approach offers a straightforward method for the synthesis of multi-functional $\mathrm{CF}_{2}$-containing compounds from easily accessible $\mathrm{CF}_{3}$ sources (Fig. 1A). 


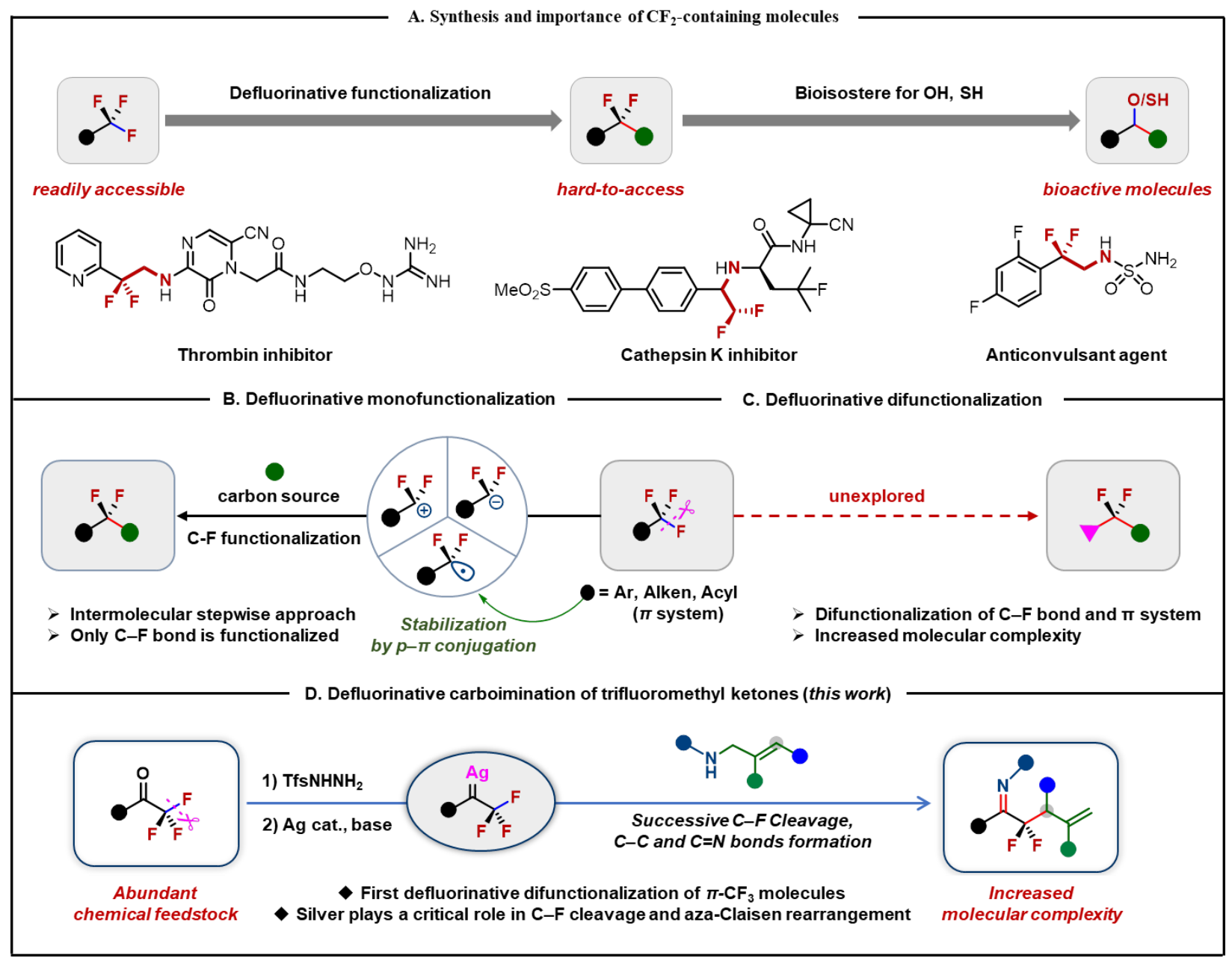

Fig. 1. Strategies for selective defluorinative carbofunctionalization of $\pi-C_{3}$ molecules. (A) Synthesis and importance of $\mathrm{CF}_{2}$-containing molecules. (B) Defluorinative monofunctionalization. (C) Defluorinative difunctionalization. (D) Approach described herein: Defluorinative carboimination of trifluoromethyl ketones. Tfs: 2-(trifluoromethyl)benzenesulfonyl.

\section{Results and discussion}

The reaction conditions were initially investigated by employing the reaction of $N$ triftosylhydrazone (1a) and $N$-allylaniline (2) as a model and varying the transition-metal catalysts. The results showed that only $\mathrm{Tp}^{\mathrm{Br} 3} \mathrm{Ag}$ proved to be effective for this tandem reaction, using $\mathrm{Cs}_{2} \mathrm{CO}_{3}$ as a base in toluene at $120^{\circ} \mathrm{C}$, obtaining the desired imine product (3) in $92 \%$ yield (For details, see Supporting Information, Table S1). With the optimal reaction conditions in hand, we first examined the scope of this defluorinative carboimination reaction using a variety of allylamines (Scheme 1A). The carboimination reaction proceeds in high yield with various $N$-aryl allylamines bearing electron-donating, electron-neutral, and electron-withdrawing substituents on the aromatic ring (3-18). Furthermore, we were pleased to find that a wide range of $N$-alkyl allylamines also proved to be effective reaction partners, and the length or bulkiness of the alkyl chain had no significantly effect on efficiency (19-36). Notably, the reaction was well compatible with a range of functional groups (e.g., $\mathrm{Cl}, \mathrm{Br}$, ether, $\mathrm{OBn}$, alkylamine, ester, $\mathrm{C}=\mathrm{C}$ double bond) commonly encountered in organic synthesis. When $N$-allylbut-2-en-1-amine was used, the aza-Claisen rearrangement selectively occurred in the less hindered terminal double bond, providing the 
product 36 in 75\% yield. The position of substituents on the double bond of allylamines has a remarkable effect on their reactivity. For example, $N$-phenyl allylanilines, having alkyl, aryl, halogens or $-\mathrm{CH}_{2} \mathrm{OBn} \alpha$ to amine, all reacted efficiently with $\mathbf{1 a}$ to afford the corresponding $\alpha, \alpha-$ difluoroimines (37-44) in good to excellent yield. In contrast, the substrate with internal double bond produced the desired product $\mathbf{4 5}$ in $22 \%$ yield only, while an azabicyclo[2.1.1] hexane $\mathbf{4 5}^{\prime}$ was obtained in $66 \%$ yield. The formation of $\mathbf{4 5}$ may be explained via an intramolecular [2+2]cycloaddition pathway, probably because the increased steric hindrance has influenced the outcome of the [3,3]-sigmatropic reaction of $N$-allyl difluoroenamines.(50) To further examine the practicality of this method, the applications to a local anesthetic Benzocaine and natural products Perillaldehyde and Citronellol derived allylamines were performed under the standard conditions, which all smoothly afforded the corresponding products $\mathbf{4 6 - 4 8}$ in $51-87 \%$ yield. This difunctionalization methodology can also be used to perform the synthesis of more complex compounds containing the $\mathrm{CF}_{2}$ unit, as exemplified by compound $\mathbf{4 9}$ which was obtained in one step by double carboimination of a bis-allylaniline substrate.

We next turned our attention to the reaction component of $N$-triftosylhydrazones, which were readily prepared in high yield by the condensation of trifluoromethyl ketones with $\mathrm{TfsNHNH}_{2}$. As shown in Scheme 1B, a wide variety of trifluoromethyl $N$-triftosylhydrazones reacted smoothly with $N$-allylaniline 2a, affording the corresponding $\alpha, \alpha$ - difluoroimines (50-65) in good to high yield. The substituents such as alkyl (51 and 57), alkoxy (50 and 58-60), phenyl (52 and 61), trifluoromethoxy $(\mathbf{5 3})$, and halogen $(\mathbf{5 4 - 5 6}, \mathbf{5 8})$ were well tolerated. Furthermore, a range of $O$ and $S$-containing heteroaromatics of interest for medicinal chemistry were tolerated and usually obtained in good yield (63-65).

In view of the increasing applications of $\beta$-difluoroalkylamines in drug discovery (2), we questioned whether it would be possible to ccess $\beta$-difluoroalkylamines products directly from trifluoromethyl ketones in a two-step, one-pot process consisting of carboimination of trifluoromethyl ketones, followed by reduction of $\alpha, \alpha$-difluoroimines. We were pleased to find that using phenyl trifluoromethyl ketone $N$-triftosylhydrazone (1a) as the $\mathrm{CF}_{2}$ source, a variety of allylamines efficiently underwent the carboimination and subsequent reduction of the resulted imines with $\mathrm{NaBH}_{4}$ simply in one-pot operation, affording the desired $\beta$-difluoroalkylamines products 66-80 in $65-87 \%$ yield. Moreover, the $N$-unprotected allylamine also proved to be a suitable substrate and resulted in the corresponding primary amine product $\mathbf{8 1}$, despite of a low yield (40\%) observed. Taken together, these results have demonstrated the usefulness of such a step-economic and operationally simple method for the synthesis of medicinally relevant $\beta$ difluoroalkylamines (2), from readily available trifluoromethyl ketones and allylamines.

All these compounds summarized in Scheme 1 are newly synthesized and hard to be accessed by other conventional methods. To explore the synthetic utility of this method, we carried out the gram-scale syntheses and further transformations, using the compounds $\mathbf{3}$ and $\mathbf{6 8}$ as the typical examples (Fig. 2). The reaction of $N$-triftosylhydrazone (1a) and $N$-allylaniline (2) was carried out at a $5 \mathrm{mmol}$ scale and produced $\alpha, \alpha$-difluoroimine 3 in $87 \%$ yield and $\beta$-difluoroalkylamine $\mathbf{6 8}$ in $80 \%$ yield, respectively, under the standard carboimination and carboamination conditions. These two multi-functional products could act as versatile building blocks for the synthesis of a variety of $\mathrm{CF}_{2}$-containing organic molecules. For instance, the rhenium-catalyzed [3+2] annulation of imine $\mathbf{3}$ and benzyl isocyanate gave an iminoisoindolinone $\mathbf{8 2}$ in 73\% yield, which represents a class of biologically interesting $\mathrm{CF}_{2}-$ 
Submitted Manuscript: Confidential

Template revised February 2021

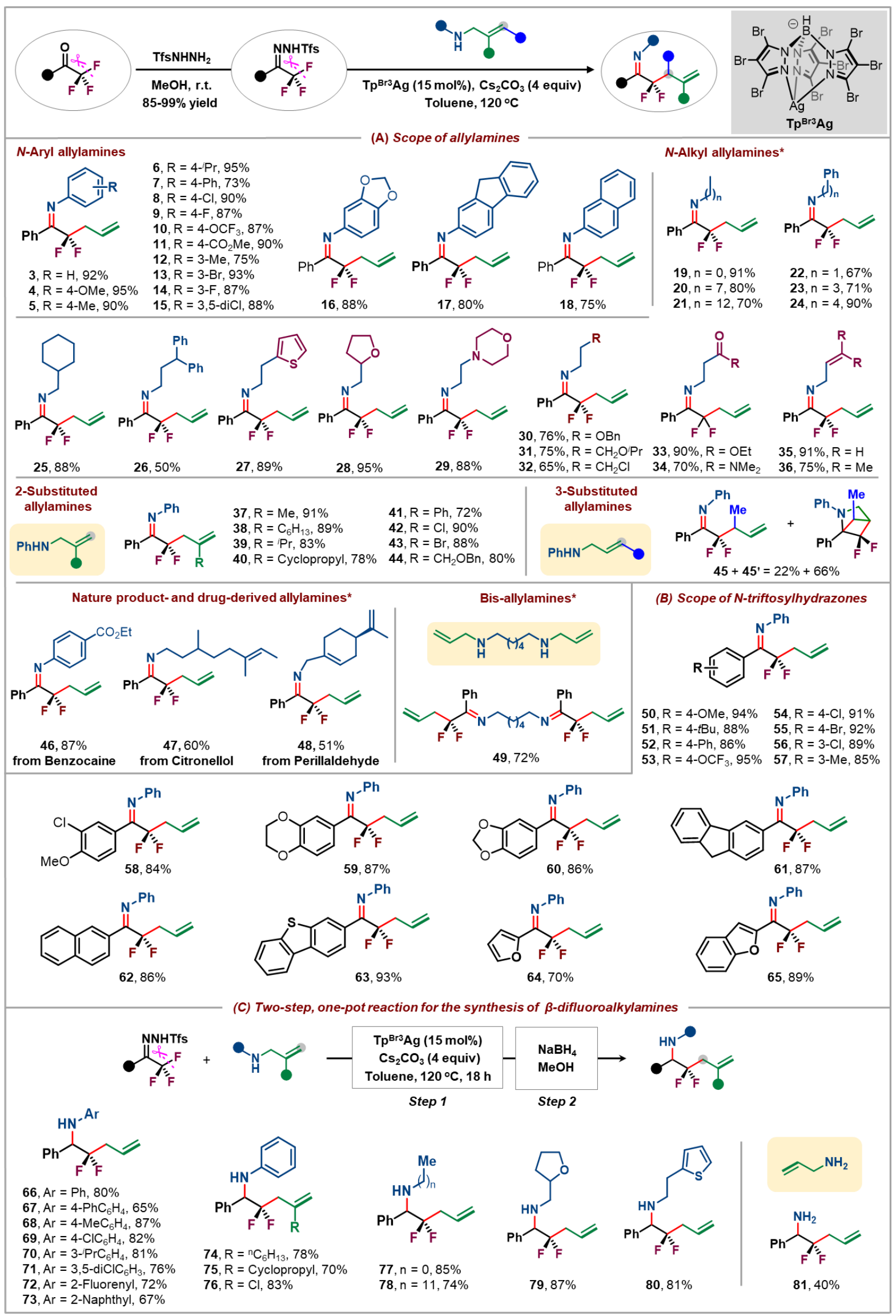


Scheme 1. A) Reaction conditions for step 1: all reactions were carried out with allylamine (0.2 mmol, 1.0 equiv), $N$-triftosylhydrazone ( $0.4 \mathrm{mmol}, 2.0$ equiv), $\mathrm{Cs}_{2} \mathrm{CO}_{3}(0.8 \mathrm{mmol}, 4.0$ equiv), $\mathrm{Tp}^{\mathrm{Br} 3} \mathrm{Ag}(15 \mathrm{~mol} \%)$ in toluene $(5 \mathrm{~mL})$ at $120{ }^{\circ} \mathrm{C}$ for $18 \mathrm{~h}$. ${ }^{*}$ Reactions were carried out with $\mathrm{Tp}{ }^{\mathrm{Br} 3} \mathrm{Ag}$ $\left(25 \mathrm{~mol} \%\right.$ ) at $80{ }^{\circ} \mathrm{C}$ for $8 \mathrm{~h}$, then $120^{\circ} \mathrm{C}$ for $12 \mathrm{~h}$. All yield refers to isolated yield. B) Reaction conditions for step 2: step 1 was complete, then removal of $\mathrm{Ag}$ catalyst and toluene from the residue were added $\mathrm{NaBH}_{4}\left(2.5\right.$ equiv) and $\mathrm{CH}_{3} \mathrm{OH}(2 \mathrm{~mL})$.

containing azaheterocycles containing a quaternary carbon center (51). Moreover, the difluoromethyl ketone 83 and the dibromide $\mathbf{8 4}$ were obtained in high yield by the treatment of $\mathbf{3}$ with silica gel and hydrobromic acid, respectively (52). On the other hand, a number of azaheterocycles containing a $\mathrm{CF}_{2}$ unit in the skeleton were prepared in high yield through the intramolecular aminofunctionalization of $\mathbf{6 8}$. For example, the treatment of 68 with NIS produced a thermodynamic product 5-iodopiperidine $\mathbf{8 5}$ in $90 \%$ yield (53), while a kinetically favored pyrrolidine 86 was obtained when using NBS instead of NIS, in which the phenyl ring was also brominated at the para-position simultaneously. Moreover, a SCN-containing pyrrolidine 87, a key precursor for the synthesis of diverse organosulfur compounds (54-55), could be prepared by intramolecular aminothiocyanation of 68 (56).

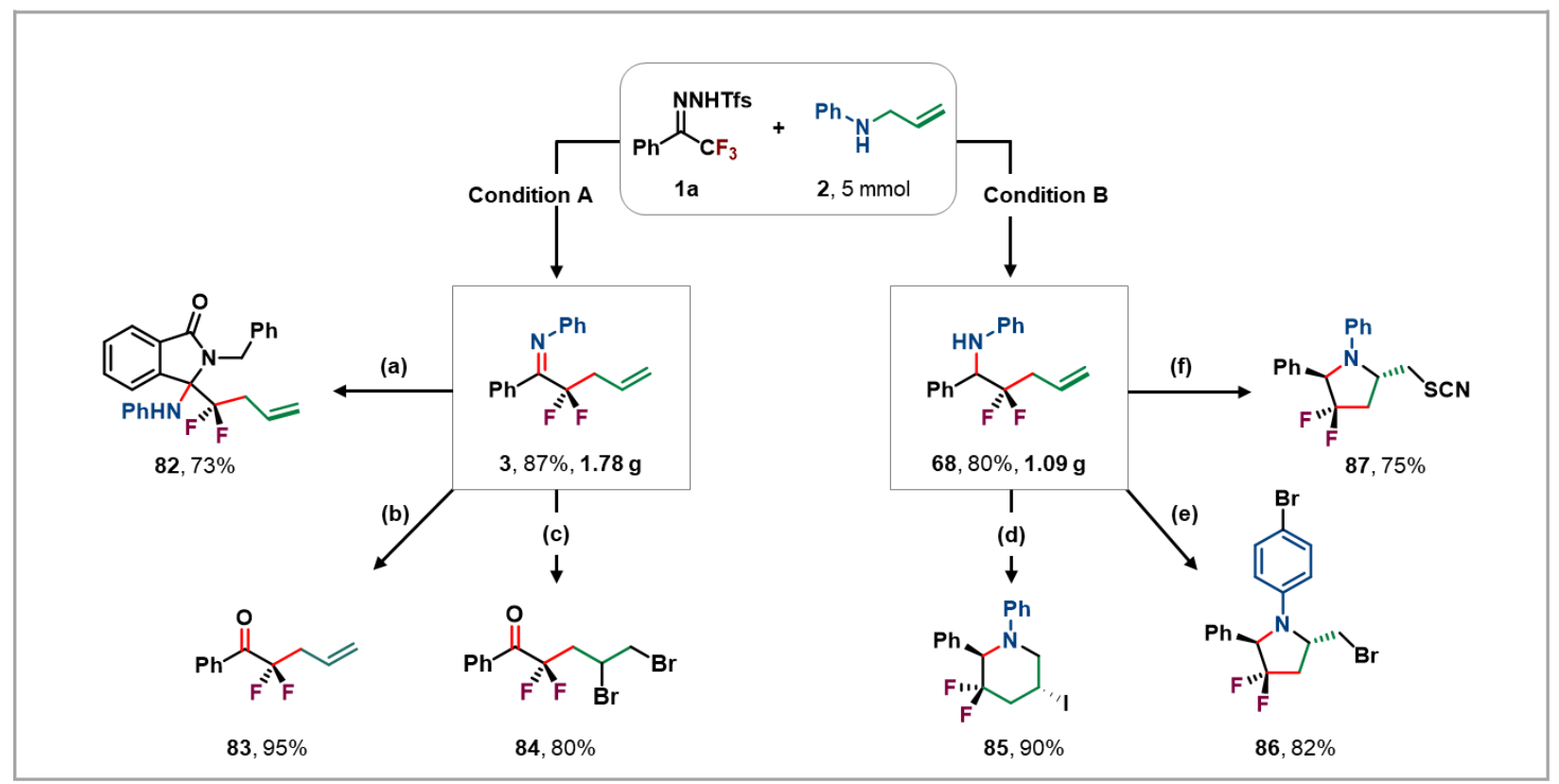

Fig. 2. Conditions A: $1 \mathrm{a}\left(10 \mathrm{mmol}, 2.0\right.$ equiv), 2 (5 mmol, 1.0 equiv), $\mathrm{Cs}_{2} \mathrm{CO}_{3}(20 \mathrm{mmol}, 4.0$ equiv) and $\mathrm{Tp}^{\mathrm{Br} 3} \mathrm{Ag}(15 \mathrm{~mol} \%)$ in toluene $(40 \mathrm{~mL})$ at $120^{\circ} \mathrm{C}$ for $18 \mathrm{~h}$. Conditions B: $1 \mathbf{a}(10 \mathrm{mmol}$, 2.0 equiv), 2 (5 mmol, 1.0 equiv), $\mathrm{Cs}_{2} \mathrm{CO}_{3}$ (20 mmol, 4.0 equiv) and $\mathrm{Tp}^{\mathrm{Br} 3} \mathrm{Ag}(15 \mathrm{~mol} \%$ ) in toluene $(40 \mathrm{~mL})$ at $120{ }^{\circ} \mathrm{C}$ for $18 \mathrm{~h}$; then removal of $\mathrm{Ag}$ catalyst and toluene from the residue were added $\mathrm{NaBH}_{4}$ (2.5 equiv), $\mathrm{CH}_{3} \mathrm{OH}(20 \mathrm{~mL})$. (a) 3 ( $\left.0.3 \mathrm{mmol}\right)$, 4-methylbenzyl isocyanate $(0.6 \mathrm{mmol}, 2.0$ equiv), $\operatorname{Re}_{2} \mathrm{CO}_{10}\left(0.03 \mathrm{mmol}, 0.1\right.$ equiv), $o$-xylene $(3 \mathrm{~mL})$, under $\mathrm{Ar}$ at $150{ }^{\circ} \mathrm{C}$ for $60 \mathrm{~h}$. (b) $3(0.3$ $\mathrm{mmol}), \mathrm{HBr}\left(48 \% \mathrm{aq}, 5.0\right.$ equiv), DMSO (1 mL), $\mathrm{CHCl}_{3}(1 \mathrm{~mL}), 25^{\circ} \mathrm{C}$. (c) Stirred in $\mathrm{CH}_{2} \mathrm{Cl}_{2}(2$ $\mathrm{mL}$ ) with silica gel at room temperature, overnight. (d) 68 ( $0.3 \mathrm{mmol}, 1.0$ equiv), NIS (0.6 mmol, 2.0 equiv), $\mathrm{CH}_{2} \mathrm{Cl}_{2}(2 \mathrm{ml}), 25^{\circ} \mathrm{C}, 10 \mathrm{~min}$. (e) 68 ( $0.3 \mathrm{mmol}, 1.0$ equiv), L-Proline ( $\left.30 \mathrm{~mol} \%\right)$, NBS 
(0.6 mmol, 2.0 equiv), THF ( $3 \mathrm{~mL})$ at $0{ }^{\circ} \mathrm{C}$. (f) 68 ( $0.2 \mathrm{mmol}, 1.0$ equiv), $\mathrm{NaSCN}$ (0.6 mmol, 3.0 equiv) and $\mathrm{I}_{2}(0.6 \mathrm{mmol}, 3.0$ equiv) in EtOAc $(3 \mathrm{~mL})$.

\section{Mechanistic investigations}

To gain more insights into the proposed mechanism in Figure 1D and the origin of chemoselectivity, experimental studies and DFT calculations were conducted. First, the key $N$ allyl difluoroenamine intermediate $\mathbf{8 8}$ was successfully isolated in $75 \%$ yield by ceasing the reaction at $40 \mathrm{~min}$ (Fig. 3A, left). Subjection of $\mathbf{8 8}$ to the standard reaction conditions resulted in product 3 in $92 \%$ yield, whereas in the absence of silver catalyst only $60 \%$ yield was obtained. These results indicate that the silver catalyst facilitates the aza-Claisen rearrangement of $\mathbf{8 8}$ that typically requires harsh reaction conditions (49). Moreover, the possibility that the reaction proceeds through the sequential formation of an amine intermediate by $\mathrm{N}-\mathrm{H}$ carbene insertion (5760) and then the elimination of $\mathrm{HF}$ to give intermediate $\mathbf{8 8}$ was excluded by the designed experiment of separately synthesized amine $\mathbf{8 9}$, because no reaction was observed under the standard conditions (Fig. 3A, right).

More mechanistic information was obtained by density functional theory (DFT) calculations that were partly displayed in Figure 3B with an ammonium ylide Int2 as the starting point, which was readily generated in situ from silver carbene and $N$-allylaniline $\mathbf{2}$ with an energy barrier of 3.6 $\mathrm{kcal} \mathrm{mol}^{-1}$ (For details, see Supporting Information, Fig. S1). The results indicate that Int 2 could undergo selective HF elimination to form Ag-coordinated gem-difluorovinylamine Int3 via a fivemembered ring transition state TS2 $\left(\Delta \Delta \mathrm{G}^{\ddagger}=20.8 \mathrm{kcal} \mathrm{mol}^{-1}\right)$, rather than proton transfer to give an $\mathrm{N}-\mathrm{H}$ insertion product 89 via TS2' $\left(\Delta \Delta \mathrm{G}^{\ddagger}=31.5 \mathrm{kcal} \mathrm{mol}^{-1}\right.$. For details, see Supporting Information, Fig. S2), which is consistent with above experimental observation. To clarify the origin of the chemoselectivity, HOMO analysis of Int2 was performed and showed that the symmetry matching of $\mathrm{F}$ and $\mathrm{H}$ atoms favors the elimination of $\mathrm{HF}$, while the symmetry of carbene carbon and $\mathrm{H}$ does not match. The single bond rotation of Int3 leads to an intermediate Int4, which then converts to product $\mathbf{3}$ via TS3 by aza-Claisen rearrangement with an energy barrier of 23.2 $\mathrm{kcal} \mathrm{mol}^{-1}$, clearly being the rate-determining step. Alternatively, gem-difluorovinylamine Int3' (compound 88), without coordinated Ag catalyst, could undergo a thermal aza-Claisen rearrangement, albeit with much higher energy barrier (TS3', $\Delta \Delta \mathrm{G}^{\ddagger}=28.9 \mathrm{kcal} \mathrm{mol}^{-1}$ ), thus highlighting the role of silver catalyst capable of facilitating the aza-Claisen rearrangement. The effect of silver was further analyzed with the help of NBO charge analysis of Int4 and Int4', respectively. It was found that the weak coordination of $\mathrm{Ag}$ to $\mathrm{N}$ in $\mathrm{Int} 4$ enhances the $\mathrm{C}-\mathrm{N}$ bond polarity and renders it more easy to cleave, as indicated by the facts that the NBO charge difference increased from 0.17 of Int4' to 0.24 of Int4 and the $\mathrm{C}-\mathrm{N}$ bond length increased from $1.47 \AA$ in Int4' to $1.50 \AA$ in Int4. Furthermore, the color-filled reduced density gradient (RDG) isosurface analysis shows a strong interaction between $\mathrm{Ag}$ and $\mathrm{N}$ atoms and a weak $\mathrm{Br} \cdots \pi$ interaction between the $\mathrm{Tp}^{\mathrm{Br} 3}$ ligand and the benzene ring, both of which could stabilize the transition state TS3 (for RDG of TS3', see Supporting Information, Fig. S3). Collectively, the reaction mechanism involves the initial formation of a silver carbene, followed by nucleophilic addition of an allylamine to give a key ammonium ylide intermediate, which then triggers the selective $\mathrm{C}-\mathrm{F}$ bond cleavage by $\mathrm{HF}$ elimination and subsequent formation of $\mathrm{C}-\mathrm{C}$ and $\mathrm{C}=\mathrm{N}$ bonds by aza-Claisen rearrangement of in situ generated gem-difluorovinylamine. During this process, $\mathrm{Tp}^{\mathrm{Br} 3} \mathrm{Ag}$ plays a critical role, especially in the stages of $\mathrm{C}-\mathrm{F}$ bond cleavage and aza-Claisen rearrangement. 


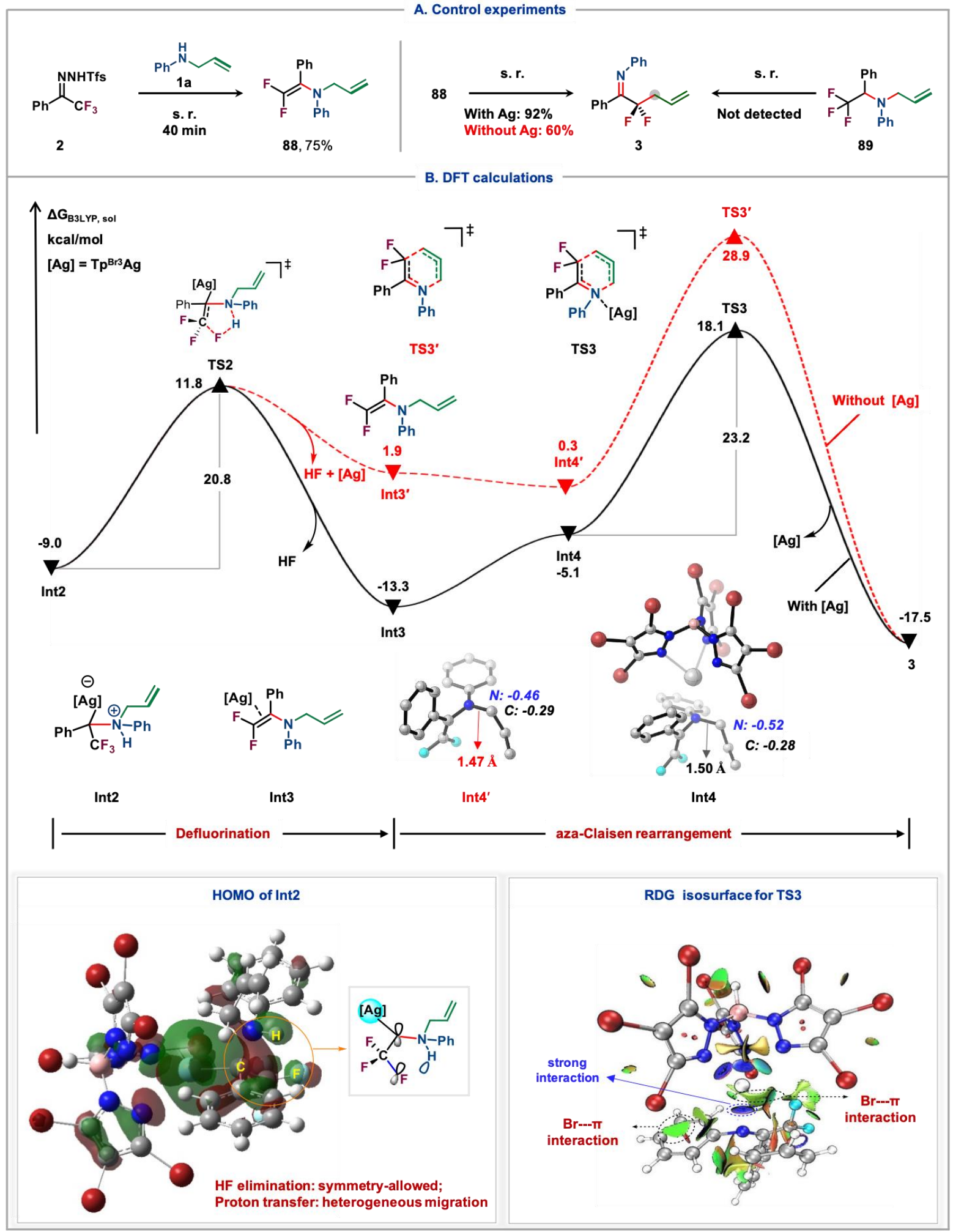

Fig. 3. Mechanistic studies. (A) Control experiments. (B) A plausible mechanism based on DFTcomputed free-energy profile at the SMD (toluene)//B3LYP/6-31G(d,p)-SDD(Ag,Br) level of theory $\left(\Delta \mathrm{G}\right.$, in $\left.\mathrm{kcal} \cdot \mathrm{mol}^{-1}\right)$. 


\section{Conclusion}

In summary, we have developed a defluorinative carboimination reaction of trifluoromethyl ketones through a conceptually distinct strategy of carbene-initiated rearrangement, which affords a variety of otherwise hardly accessible $\alpha, \alpha$-difluoroimines. This report, which represents the first example of simultaneous difunctionalization of $\mathrm{C}-\mathrm{F}$ bond and $\pi$-system of $\pi$ - $\mathrm{CF}_{3}$ molecules, provides a new approach to the functionalization of $\mathrm{C}\left(\mathrm{sp}^{3}\right)-\mathrm{F}$ bonds via merging of silver carbene and classical $\sigma$-rearrangement.

\section{References and Notes}

1. Y. Zhou et al., Next generation of fluorine-containing pharmaceuticals, compounds currently in phase II-III clinical trials of major pharmaceutical companies: new structural trends and therapeutic areas. Chem. Rev. 116, 422-518 (2016).

2. E. P. Gillis, K. J. Eastman, M. D. Hill, D. J. Donnelly, N. A. Meanwell, Applications of fluorine in medicinal chemistry. J. Med. Chem. 58, 83155-8359 (2015).

3. J. Wang et al., Fluorine in pharmaceutical industry: fluorine-containing drugs introduced to the market in the last decade (2001-2011). Chem. Rev, 114, 2432-2506 (2014).

4. K. Müller, C. Faeh, F. Diederich, Fluorine in pharmaceuticals: looking beyond intuition. Science, 317, 1881-1886 (2007).

5. T. Fujiwara, D. O’Hagan, Successful fluorine-containing herbicide agrochemicals. J. Fluor. Chem. 167, 16-29 (2014).

6. R. Berger, G. Resnati, P. Metrangolo, E. Weber and J. Hulliger, Organic fluorine compounds: a great opportunity for enhanced materials properties. Chem. Soc. Rev. 40, 3496-3508 (2011).

7. D. O'Hagan, Understanding organofluorine chemistry. An Introduction to the C-F Bond. Chem. Soc. Rev. 37, 308-319 (2008).

8. W. K. Hagmann, The many roles for fluorine in medicinal chemistry. J. Med. Chem. 51, 43594369 (2008).

9. Y. Zafrani et al., Difluoromethyl bioisostere: examining the "lipophilic hydrogen bond donor" concept. J. Med. Chem. 60, 797-804 (2017).

10. C. D. Sessler et al., CF 2 H, a hydrogen bond donor. J. Am. Chem. Soc. 139, 9325-9332 (2017).

11. Z. Feng, Y. L. Xiao, X. G. Zhang, Transition-metal (Cu, Pd, Ni)-catalyzed difluoroalkylation via cross-coupling with difluoroalkyl halides. Acc. Chem. Res. 51, 2264-2278 (2018).

12. C. F. Ni, M. Y. Hu, J. B. Hu, Good partnership between sulfur and fluorine: fulfur-based fluorination and fluoroalkylation feagents for organic synthesis. Chem. Rev. 115, 765-825 (2015).

13. X. Y. Yang, T. Wu, R. J. Phipps, F. D. Toste, Advances in catalytic enantioselective fluorination, mono-, di-, and trifluoromethylation, and trifluoromethylthiolation reactions. Chem. Rev. 2015, $115,826-870$ (2015).

14. D. E. Yerien, S. B.Vallejo, A. Postigo, Difluoromethylation reactions of organic compounds. Chem. Eur. J. 23, 14676-14701 (2017).

15. X. X. Ma, Q. L. Song, Recent progress on selective deconstructive modes of halodifluoromethyl and trifluoromethyl-containing reagents. Chem. Soc. Rev. 49, 9197-9219 (2020).

16. X. Zhang et al., Phosphorus-mediated $\mathrm{sp}^{2}-\mathrm{sp}^{3}$ couplings for $\mathrm{C}-\mathrm{H}$ fluoroalkylation of azines. Nature 594, 217-222 (2021).

17. X. P. Fu et al., Controllable catalytic difluorocarbene transfer enables access to diversified fluoroalkylated arenes. Nat. Chem. 11, 948-956 (2019). 
18. R. R. Merchant et al., Modular radical cross-coupling withsulfones enables access to $\mathrm{sp}^{3}$ rich(fluoro)alkylated scaffolds. Science 360, 75-80 (2018).

19. M. P. Wiesenfeldt, Z. Nairoukh, W. Li, F. Glorius, Hydrogenation of fluoroarenes: Direct access to all-cis-(multi)fluorinated cycloalkanes. Science 357, 908-912 (2017).

20. Z. Feng, Q. Q. Min, X. P. Fu, L. An, X. G. Zhang, Chlorodifluoromethane-triggered formation of difluoromethylated arenes catalysed by palladium. Nat. Chem. 9, 918-923 (2017).

21. Y. Q. Ning, P. Sivaguru, G. Zanoni, E. A. Anderson, X. H. Bi, Synthesis of $\beta$-difluoroalkyl azides via elusive 1,2-azide migration. Chem 6, 486-496 (2020).

22. T. Furuya, A. S. Kamlet, T. Ritter, Catalysis for fluorination and trifluoromethylation. Nature 473, 470-477 (2011).

23. W. Wu, Z. Q. Weng, Synthesis of aryl trifluoromethyl ketones. Synthesis 50, 1958 - 1964 (2018).

24. F. Jaroschik, Picking one out of three: selective single $\mathrm{C}-\mathrm{F}$ activation in trifluoromethyl groups. Chem. Eur. J. 24, 14572-14582 (2018).

25. T. Ahrens, J. Kohlmann, M. Ahrens, T. Braun, Functionalization of fluorinated molecules by transition-metal-mediated $\mathrm{C}-\mathrm{F}$ bond activation to access fluorinated building blocks. Chem. Rev. 115, 931-972 (2015).

26. T. T. Simur, T. Ye, Y. J. Yu, F. L. Zhang, Y. F. Wang, C-F bond functionalizations of trifluoromethyl groups via radical intermediates. Chem. Chem. Lett. 2021, DOI: 10.1016/j.cclet.2021.08.043.

27. H. Amii, K. Uneyama, C-F bond activation in organic synthesis. Chem. Rev. 109, 2119-2183 (2009).

28. S. Yoshida, K. Shimomori, Y. Kim, T. Hosoya, Single C-F bond cleavage of trifluoromethylarenes with an ortho-silyl group. Angew. Chem. Int. Ed. 55, 10406-10409 (2016).

29. D. Mandal, R. Gupta, A. K. Jaiswal, R. D. Young, Frustrated lewis-pair-meditated selective single fluoride substitution in trifluoromethyl groups. J. Am. Chem. Soc. 142, 2572-2578 (2020).

30. H. Amii, Y. Hatamoto, M. Seo, K. Uneyama, A new C-F bond-cleavage route for the synthesis of octafluoro[2.2]paracyclophane. J. Org. Chem. 66, 7216-7218 (2001).

31. Y. Yamauchi, T. Fukuhara, S. Hara, H. Senboku, Electrochemical carboxylation of $\alpha, \alpha-$ difluorotoluene derivatives and its application to the synthesis of $\alpha$-fluorinated nonsteroidal anti-inflammatory drugs. Synlett 2008, 438-442 (2008).

32. Q. Shen et al., Review of recent advances in Csingle bondF bond activation of aliphatic fluorides. J. Fluor. Chem. 179, 14-22 (2015).

33. Y. C. Luo, F. F. Tong, Y. X. Zhang, C. Y. He, X. G. Zhang, Visible-light-induced palladiumcatalyzed selective defluoroarylation of trifluoromethylarenes with arylboronic acids. J. Am. Chem. Soc. 143, 13971-13979 (2021).

34. S. S.Yan et al., Visible-light photoredox-catalyzed selective carboxylation of $\mathrm{C}\left(\mathrm{sp}^{3}\right)-\mathrm{F}$ bonds with $\mathrm{CO}_{2}$. Chem 7, 3099-3113 (2021).

35. M. W. Campbell et al., Photochemical C-F activation enables defluorinative alkylation of trifluoroacetates and -acetamides. J. Am. Chem. Soc. 143, 19648-19654 (2021).

36. S. Ghosh et al., HFIP-assisted single $\mathrm{C}-\mathrm{F}$ bond activation of trifluoromethyl ketones using visible-light photoredox catalysis. Angew. Chem. Int. Ed. 2021, DOI:10.1002/anie.202115272.

37. J. B. I. Sap et al., Organophotoredox hydrodefluorination of trifluoromethylarenes with translational applicability to drug discovery. J. Am. Chem. Soc. 142, 9181-9187 (2020).

38. C. S. Luo, J. S. Bandar, Selective defluoroallylation of trifluoromethylarenes. J. Am. Chem. 
Soc. 141, 14120-14125 (2019).

39. D. B. Vogt, C. P. Seath, H. B. Wang, N. T. Jui, Selective C-F functionalization of unactivated trifluoromethylarenes. J. Am. Chem. Soc. 141, 13203-13211 (2019).

40. H. B. Wang, N. T. Jui, Catalytic defluoroalkylation of trifluoromethylaromatics with unactivated alkenes. J. Am. Chem. Soc. 140, 163-166 (2018).

41. K. Chen, N. Berg, R. Gschwind, B. König, Selective single C( $\left.\mathrm{sp}^{3}\right)-\mathrm{F}$ bond cleavage in trifluoromethylarenes: merging visible-light catalysis with lewis acid activation. J. Am. Chem. Soc. 139, 18444-18447 (2017).

42. Y. J. Yu et al., Sequential C-F bond functionalizations of trifluoroacetamides and acetates via spin-center shifts. Science 371, 1232-1240 (2021).

43. Y. Xia, D. Qiu, J. B. Wang, Transition-metal-catalyzed cross-couplings through carbene migratory insertion. Chem. Rev. 117, 13810-13889 (2017).

44. P. K. Mykhailiuk, 2,2,2-trifluorodiazoethane $\left(\mathrm{CF}_{3} \mathrm{CHN}_{2}\right)$ : a long journey since 1943. Chem. Rev. 120, 12718-12755 (2020).

45. C. J. Li, X. H. Bi, Silver Catalysis in Organic Synthesis, (Wiley, 2019).

46. A. Caballero, Silver-catalyzed $\mathrm{C}-\mathrm{C}$ Bond Formation between methane and ethyl diazoacetate in supercritical $\mathrm{CO}_{2}$. Science 332, 835-838 (2011).

47. Z. H. Liu et al., Site-selective $\mathrm{C}-\mathrm{H}$ benzylation of alkanes with $N$-Triftosylhydrazones leading to alkyl aromatics. Chem 6, 2110-2124 (2020).

48. X. L. Zhang, Z. H. Liu, P. Sivaguru, X. H. Bi, Silver carbenoids derived from diazo compounds: A historical perspective on challenges and opportunities. Chem Catalysis 1, 599$630(2021)$.

49. U. Nubbemeyer, Recent advances in charge-accelerated aza-claisen rearrangements. Top Curr Chem 244, 149-213 (2005).

50. H. Amii, Y. Ichihara, T. Nakagawa, T. Kobayashia, K. Uneyama, Unusual reactions of $N-$ allylic difluoroenamines under thermal conditions. Chem. Commun. 2003, 2902-2903 (2003).

51. S. S. Zhang et al., The [3+2] annulation of $\mathrm{CF}_{3}$-ketimines by $\mathrm{Re}$ catalysis: access to $\mathrm{CF}_{3}-$ containing amino heterocycles and polyamides. iscience, 23, 101705 (2020).

52. G. K. Dewkar, S. V. Narina, A. Sudalai, $\mathrm{NaIO}_{4}$-mediated selective oxidative halogenation of alkenes and aromatics using alkali metal halides. Org. Lett. 5, 4501-4504 (2003).

53. F. Diaba, J. Bonjoch, NMR evidence of the kinetic and thermodynamic products in the NIS promoted cyclization of 1-phenyl-4-pentenylamines. Synthesis and reactivity of trans-2phenyl-5-iodopiperidines. Chem. Commun. 47, 3251-3253 (2011).

54. A. Houmam, E. M. Hamed, Ian. W. J. Still, A unique autocatalytic process and evidence for a concerted-stepwise mechanism transition in the dissociative electron-transfer reduction of aryl thiocyanates. J. Am. Chem. Soc. 125, 7258-7265 (2003).

55. M. Pawliczek, L. K. B. Garve, D. B. Werz, Activation of aryl thiocyanates followed by aryne insertion: access to 1,2-thiobenzonitriles. Org. Lett. 17, 1716-1719 (2015).

56. Y. Y. Feng et al., Aerobic intramolecular aminothiocyanation of unactivated alkenes promoted by in situ generated iodine thiocyanate. Tetrahedron 74, 2669-2676 (2018).

57. M. P. Doyle, M. A. McKervey, T. Ye, Modern Catalytic Methods for Organic Synthesis with Diazo Compounds, (Wiley, 1998).

58. S. F. Zhu, Q. L. Zhou, Transition-Metal-Catalyzed Enantioselective Heteroatom-Hydrogen Bond Insertion Reactions. Acc. Chem. Res. 45, 1365-1377 (2012).

59. D. Gillingham, N. Fei, Catalytic X-H Insertion Reactions Based on Carbenoids. Chem. Soc. Rev. 42, 4918-4931 (2013).

60. S. Chuprakov, B. T. Worrell, N. Selander, R. K. Sit, V. V. Fokin, Stereoselective 1,3-insertions of rhodium(II) azavinyl carbenes. J. Am. Chem. Soc. 136, 195-202 (2014). 


\section{Acknowledgments:}

Funding: This work was supported by The National Natural Science Foundation of China (NSFC) 21871043 and 21961130376, Department of Science and Technology of Jilin Province 20180101185JC, 20190701012GH and 20200801065GH, and the Fundamental Research Funds for the Central Universities 2412019ZD001 and 2412020ZD003.

Author contributions: X.Z., Y.N. and Z.L. contributed equally to this work. X.Z., Y.N., Z.L. and S.L. performed the experimental investigations and theoretical calculations. Y.N., Z.L. and X.B. conceived the concept, designed the project, analyzed the data, and together with G.Z. discussed the results and prepared this manuscript.

\section{Competing interests:}

Authors declare that they have no competing interests.

Data and materials availability: All data are available in the main text or the supplementary materials. 